\title{
Diagnostic Value of Urinary Steroid Profiling in the Evaluation of Adrenal Tumors
}

\author{
T. M. A. Kerkhofs ${ }^{1}$ - M. N. Kerstens ${ }^{2}$ - I. P. Kema ${ }^{3}$ - T. P. Willems ${ }^{4} \cdot$ H. R. Haak ${ }^{1,5,6}$
}

Received: 21 January 2015 / Accepted: 5 May 2015 /Published online: 19 May 2015

(C) The Author(s) 2015. This article is published with open access at Springerlink.com

\begin{abstract}
Radiological examination may unexpectedly reveal an adrenal mass. Current algorithms for differentiating between benign and malignant lesions mainly rely on size and densitometry on unenhanced $\mathrm{CT}$, which have limited specificity. We examined the diagnostic value of urinary steroid profiling by gas chromatography/mass-spectrometry (GC/MS) in differentiating between benign and malignant adrenal tumors. A retrospective study in two referral centers for patients with adrenal disease was performed. All urinary steroid profiles ordered for evaluation of an adrenal tumor between January 2000 and November 2011 were examined. Patients were diagnosed with adrenal cortical carcinoma (ACC), adrenal cortical adenoma (ACA), or other adrenal mass. Results of hormonal measurements, imaging studies, pathology reports, and clinical outcome were retrieved from medical records. The diagnostic value of individual urinary steroid metabolites
\end{abstract}

T. M. A. Kerkhofs

t.kerkhofs@mmc.nl

1 Department of Internal Medicine, Máxima Medical Center, Ds. Th. Fliednerstraat 1, 5631 BM Eindhoven, The Netherlands

2 Department of Endocrinology, University Medical Center Groningen, University of Groningen, Groningen, The Netherlands

3 Department of Laboratory Medicine, University Medical Center Groningen, University of Groningen, Groningen, The Netherlands

4 Department of Radiology, University Medical Center Groningen, University of Groningen, Groningen, The Netherlands

5 Department of Health Services Research and CAPHRI School for Public Health and Primary Care, Maastricht University, Maastricht, The Netherlands

6 Department of Internal Medicine, Division of General Internal Medicine, Maastricht University Medical Centre+, Maastricht, The Netherlands was determined by receiver operating characteristics analysis. Cut-off values were compared to reference values from an age and gender-standardized population of healthy controls. Eighteen steroid metabolites were excreted in significantly higher concentrations in patients with ACC $(n=27)$ compared to patients with ACA $(n=107)$ or other adrenal conditions $(n=18)$. Tetrahydro-11-deoxycortisol (THS) at a cut-off value of $2.35 \mu \mathrm{mol} / 24 \mathrm{~h}$ differentiated ACC from other adrenal disorders with $100 \%$ sensitivity and $99 \%$ specificity. Elevated urinary excretion of THS was associated with a very high sensitivity and specificity to differentiate between an ACC and a benign adrenal mass. Urinary steroid profiling might be a useful diagnostic test for the evaluation of patients with an adrenal incidentaloma.

\section{Introduction}

An adrenal incidentaloma is an adrenal mass found coincidentally during a radiologic examination performed for reasons other than evaluation for adrenal disease [1]. The estimated prevalence of adrenal incidentalomas ranges from about $0.1 \%$ for general health screening with ultrasonography to $4.4 \%$ in older subjects examined with high-resolution CT scanning [2]. Optimal clinical management of adrenal incidentalomas has not been established as none of the proposed diagnostic algorithms has been validated prospectively [1, 3-5]. Key objectives of these algorithms are to determine whether hormonal overproduction and/or malignant disease is present. The reported frequency of adrenocortical carcinoma (ACC) among patients with adrenal incidentaloma varies from $1.2-12 \%$ [5]. Assessment of malignancy risk is predominantly based on radiological characteristics such as size, shape, and attenuation value of the adrenal mass. In addition, follow-up by monitoring growth rate with repeat CT or MRI-scans at various 
intervals during 1 to 2 years after discovery is generally advised for those patients not undergoing surgery after the initial evaluation [1, 4-7]. However, a strategy of repeat imaging is associated with certain risks for the patient and is unlikely to be cost-effective [8]. Urinary steroid profiling (USP) might offer an alternative diagnostic tool for discriminating between ACC and non-ACC in individuals presenting with an adrenal incidentaloma, as it has been shown that ACC is often accompanied by alterations in the urinary steroid metabolome [9-11]. Currently, only few studies have examined the potential diagnostic value of USP in individuals harboring an adrenal tumor [12-15]. Except for the study by Arlt et al. [13], these studies described a small number of subjects. Therefore, the primary objective of our study was to determine the diagnostic performance of USP in differentiating ACC from nonACC in a large cohort of patients with adrenal tumors.

\section{Patients and Methods}

Both Máxima Medical Center (MMC) and University Medical Center Groningen (UMCG) are referral centers for patients with adrenal disease. We retrospectively analyzed all urinary steroid profiles ordered for evaluation of an adrenal tumor at UMCG and MMC from January 1, 2000 until November 1, 2011. In addition, we included all adult patients with ACC diagnosed from January 1, 2011 until January 1, 2014 in whom a baseline urinary steroid profile was performed. The corresponding medical records were examined and the following data were retrieved: age, gender, symptoms, and signs, laboratory measurements (i.e., hormonal tests), imaging studies, treatment, pathology reports, clinical outcome, and follow-up.

Endocrine activity of the tumor was determined based on the results of locally applied hormonal assays. Glucocorticoid excess was defined as an abnormal result of the $1 \mathrm{mg}$ overnight dexamethasone suppression test (cut-off value serum cortisol at $50 \mathrm{nmol} / \mathrm{L}$ ) and/or as an elevated $24 \mathrm{~h}$ urinary free cortisol excretion. Serum aldosterone to plasma renin ratio was determined to screen for primary aldosteronism, serum dehydro-epiandrosteronesulfate (DHEAS), and testosterone were measured to demonstrate hyperandrogenism (cut-off values based on individual age and gender-related upper reference limits). Plasma-free metanephrines or urinary fractionated metanephrines were measured to detect a pheochromocytoma. Tumor size and unenhanced CT attenuation values were collected from the original radiological examination report. In case these were not reported, the original CT studies were re-examined by an experienced radiologist.

The final diagnosis was based on either the pathological examination of the resected adrenal gland or on the clinical course including the results of follow-up imaging studies in patients who did not undergo surgery. In patients with ACC, the Weiss score (a set of nine histopathological criteria with prognostic value in adrenocortical tumors) was extracted from the original pathology reports and disease progression was staged according to the European Network for Study of Adrenal Tumors (ENSAT) staging system [16, 17]. Patients in whom a final diagnosis of pheochromocytoma was made were excluded from the present study.

Gas chromatography/mass-spectrometry (GC/MS) for determination of the USP was performed at the department of laboratory medicine of the UMCG. In summary, free and conjugated steroids were extracted from $1-\mathrm{mL}$ urine by liquidliquid extraction. Enzymatic hydrolyzation, re-extraction, and chemical derivatization formed methyloxime-trimethylsilyl ethers from steroid conjugates. An Agilent 5973 instrument operating in selected ion-monitoring (SIM) mode was used to achieve sensitive and specific detection and quantification of 22 selected steroid metabolites [18].

Reference values for USP were established in a group of healthy volunteers $(n=240)$ recruited from the LifeLines cohort, a three-generation population-based study [19]. These subjects were stratified according to gender and age, with age ranging from 20 to 79 years and each decade comprising 40 subjects (male-to-female ratio 1:1).

\section{Statistical Analysis}

Demographical characteristics were assessed using ANOVA for continuous variables and Pearson's chi-squared test for categorical variables. Between-group differences in steroid excretion were evaluated using the Kruskal-Wallis test followed by post hoc analysis using the Mann-Whitney test with Bonferroni adjustment ( $\alpha=0.008)$. Receiver operating characteristics (ROC) curves were generated for those individual urinary metabolites which displayed a significant betweengroup difference. Sensitivity and specificity were calculated at cut-off values providing highest sensitivity. Cut-off values were compared with age- and gender-dependent reference values. Correlation between histological characteristics and steroid excretion in patients with ACC was calculated using Pearson's correlation analysis and expressed as Pearson's $r$. A two-sided $P$ value $<0.05$ was considered to be significant. Data management and statistical analyses were performed using Prism 6.0 (GraphPad Software, La Jolla, USA) and SPSS 19.0 (IBM, Armonk, USA).

\section{Results}

\section{Patients}

We evaluated 152 patients with an adrenal tumor (52 males, 100 females), and demographical characteristics are summarized in Table 1. The following diagnoses 
Table 1 Clinical and radiological characteristics of 152 patients who were evaluated for an adrenal tumor

\begin{tabular}{|c|c|c|c|c|c|c|c|}
\hline & & $\begin{array}{l}\text { Total } \\
(n=152)\end{array}$ & $\begin{array}{l}\mathrm{ACC} \\
(n=27)\end{array}$ & $\begin{array}{l}\text { ACA }_{\text {functioning }} \\
(n=22)\end{array}$ & $\begin{array}{l}\mathrm{ACA}_{\text {non-functioning }} \\
(n=85)\end{array}$ & $\begin{array}{l}\text { Other } \\
(n=18)\end{array}$ & $P$ value \\
\hline \multicolumn{2}{|l|}{ Age (years) $[$ mean \pm SD] } & $56 \pm 13$ & $57 \pm 14$ & $50 \pm 12$ & $58 \pm 12$ & $54 \pm 17$ & $0.043^{*}$ \\
\hline $\operatorname{Sex}[n(\%)]$ & $\begin{array}{l}\text { Male } \\
\text { Female }\end{array}$ & $\begin{array}{l}52(34) \\
100(66)\end{array}$ & $\begin{array}{l}8(30) \\
19(70)\end{array}$ & $\begin{array}{l}6(27) \\
16(73)\end{array}$ & $\begin{array}{l}28(33) \\
57(67)\end{array}$ & $\begin{array}{l}10(56) \\
8(44)\end{array}$ & 0.219 \\
\hline $\begin{array}{l}\text { BMI }\left(\mathrm{kg} / \mathrm{m}^{2}\right) \\
\quad[\mathrm{mean} \pm \mathrm{SD}]\end{array}$ & & $28.0 \pm 5.6$ & $26.7 \pm 4.9$ & $29.1 \pm 4.4$ & $28.0 \pm 5.7$ & $28.8 \pm 7.1$ & 0.552 \\
\hline \multirow{3}{*}{$\begin{array}{l}\text { Hormonal } \\
\text { overproduction } \\
{[n(\%)]}\end{array}$} & $\begin{array}{l}\text { Glucocorticoids } \\
\text { Androgens }\end{array}$ & $\begin{array}{l}38(25) \\
14(9)\end{array}$ & $\begin{array}{l}18(67) \\
14(52)\end{array}$ & $\begin{array}{l}19(86) \\
0\end{array}$ & $\begin{array}{l}0 \\
0\end{array}$ & $\begin{array}{l}1(6) \\
0\end{array}$ & \multirow[t]{3}{*}{-} \\
\hline & Estrogens & $1(1)$ & $1(4)$ & 0 & 0 & 0 & \\
\hline & Mineralocorticoids & $4(3)$ & 0 & $3(13)$ & 0 & $1(6)$ & \\
\hline $\begin{array}{l}\text { Tumor size }(\mathrm{cm}) \\
{[\text { median (range) }]}\end{array}$ & & $\begin{array}{l}3.5 \\
\quad(0.8-17.0)\end{array}$ & $\begin{array}{l}10.0 \\
\quad(5.3-17.0)\end{array}$ & $\begin{array}{l}3.0 \\
\quad(0.9-5.0)\end{array}$ & $\begin{array}{l}2.8 \\
\quad(0.8-10.0)\end{array}$ & $\begin{array}{l}7.4 \\
\quad(2.3-14.0)\end{array}$ & $<0.001^{* *}$ \\
\hline \multirow{2}{*}{$\begin{array}{l}\text { CT densitometry } \\
\text { (HU) }[n]\end{array}$} & $\begin{array}{l}\leq 10 \\
>10\end{array}$ & $\begin{array}{l}37 \\
41\end{array}$ & $\begin{array}{l}0 \\
13\end{array}$ & $\begin{array}{l}6 \\
2\end{array}$ & $\begin{array}{l}28 \\
22\end{array}$ & $\begin{array}{l}3 \\
4\end{array}$ & \multirow[t]{2}{*}{-} \\
\hline & $\mathrm{n} / \mathrm{a}$ & $\begin{array}{l}41 \\
74\end{array}$ & 14 & 14 & 35 & 11 & \\
\hline
\end{tabular}

$P$ value for comparison between groups, n/a: unenhanced CT scan was not performed

$A C C$ adrenocortical carcinoma, $A C A$ adrenocortical adenoma, $B M I$ body mass index

*Mann-Whitney $U$ test with Bonferroni correction for comparison between individual groups $(\alpha=0.008)$ between $\mathrm{ACA}_{\text {functioning }}$ and $\mathrm{ACA}_{\text {non-functioning, }}$ $P=0.005$; other comparisons did not show significant results

**Mann-Whitney $U$ test with Bonferroni correction for comparison between individual groups $(\alpha=0.008)$ between $\mathrm{ACC}$ and $\mathrm{ACA}$ functioning, $P<0.001$;

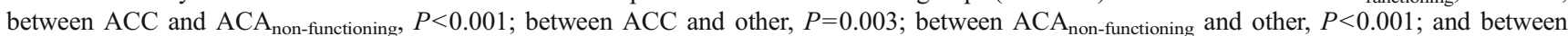
$\mathrm{ACA}_{\text {functioning }}$ and other, $P=0.001$

were established: adrenocortical carcinoma (ACC; $n=$ 27) and adrenocortical adenoma (ACA; $n=107)$. In addition, there was a mixed group of 18 patients with a variety of diagnoses: benign myelolipoma $(n=4)$, metastasis from an extra-adrenal primary tumor $(n=4)$, adrenal hyperplasia $(n=2)$, multinodular hyperplasia $(n=2)$, cavernous lymphangioma $(n=1)$, ganglioneuroma $(n=1)$, hemangioma $(n=1)$, cyst $(n=1)$, non-Hodgkin lymphoma $(n=1)$ and leiomyosarcoma $(n=1)$. The majority of these patients were analyzed because of an adrenal incidentaloma $(n=109,72 \%)$.

A diagnosis of ACC was histologically confirmed in 25 subjects (93\%). Median Weiss-score was 6 (range 4-8). In the remaining 2 patients, a clinical diagnosis of ACC was made based on imaging studies showing an adrenal tumor with metastases in combination with biochemical evidence of steroid hypersecretion. At presentation, the tumor stages according to the ENSAT classification were II $(n=10)$, III $(n=6)$ and IV $(n=11)$ [16]. Hormonal overproduction was present in 20 patients $(74 \%)$; hypercortisolism $(n=18)$, hyperandrogenism $(n=14)$, and hyperestrogenism $(n=1)$. Histological confirmation was obtained in 28 subjects with ACA $(26 \%)$ and in 13 patients from the mixed group (68\%). In the remainder of subjects, a diagnosis of ACA was established by biochemical and imaging studies as well as by clinical followup (median 52 months; range 3-167 months). Patients with functioning ACA demonstrated hypercortisolism $(n=19)$ or primary aldosteronism $(n=3)$.

\section{Radiological Characteristics}

Patients underwent radiological imaging with CT $(n=126)$ and/or MRI $(n=29)$. Median tumor size in patients with ACC was $10.0 \mathrm{~cm}$ (range $5.3-17.0 \mathrm{~cm}$ ), significantly larger than the lesion size in patients with ACA $(2.9 \mathrm{~cm}$; range 0.8 $10.0 \mathrm{~cm})$ or in patients from the mixed group $(7.4 \mathrm{~cm}$; range $2.3-14.0 \mathrm{~cm}, P<0.001$ for both; Table 1).

An unenhanced abdominal CT scan was performed in 78 patients $(51 \%)$. All adrenal lesions with attenuation value $\leq 10$ HU $(n=37)$ were found to be benign. The 41 adrenal tumors with an unenhanced attenuation value $>10 \mathrm{HU}$ included ACC $(n=13)$, ACA $(n=24)$, metastatic lesions $(n=2)$, benign myelolipoma $(n=1)$, and a leiomyosarcoma $(n=1)$. At a cutoff value of $10 \mathrm{HU}$, unenhanced CT densitometry was $100 \%$ sensitive and $57 \%$ specific for the presence of ACC.

\section{Steroid Metabolite Excretion}

Eighteen steroid metabolites were excreted in significantly larger quantities by patients with ACC compared to patients with non-ACC-related adrenal masses (Fig. 1). In contrast, patients with ACC excreted less of the metabolite allotetrahydrocorticosterone (allo-THB) compared to subjects without ACC $(P=0.019)$. There were no significant differences in individual metabolite excretion between the groups with functioning ACA, non-functioning ACA, and the mixed group. 

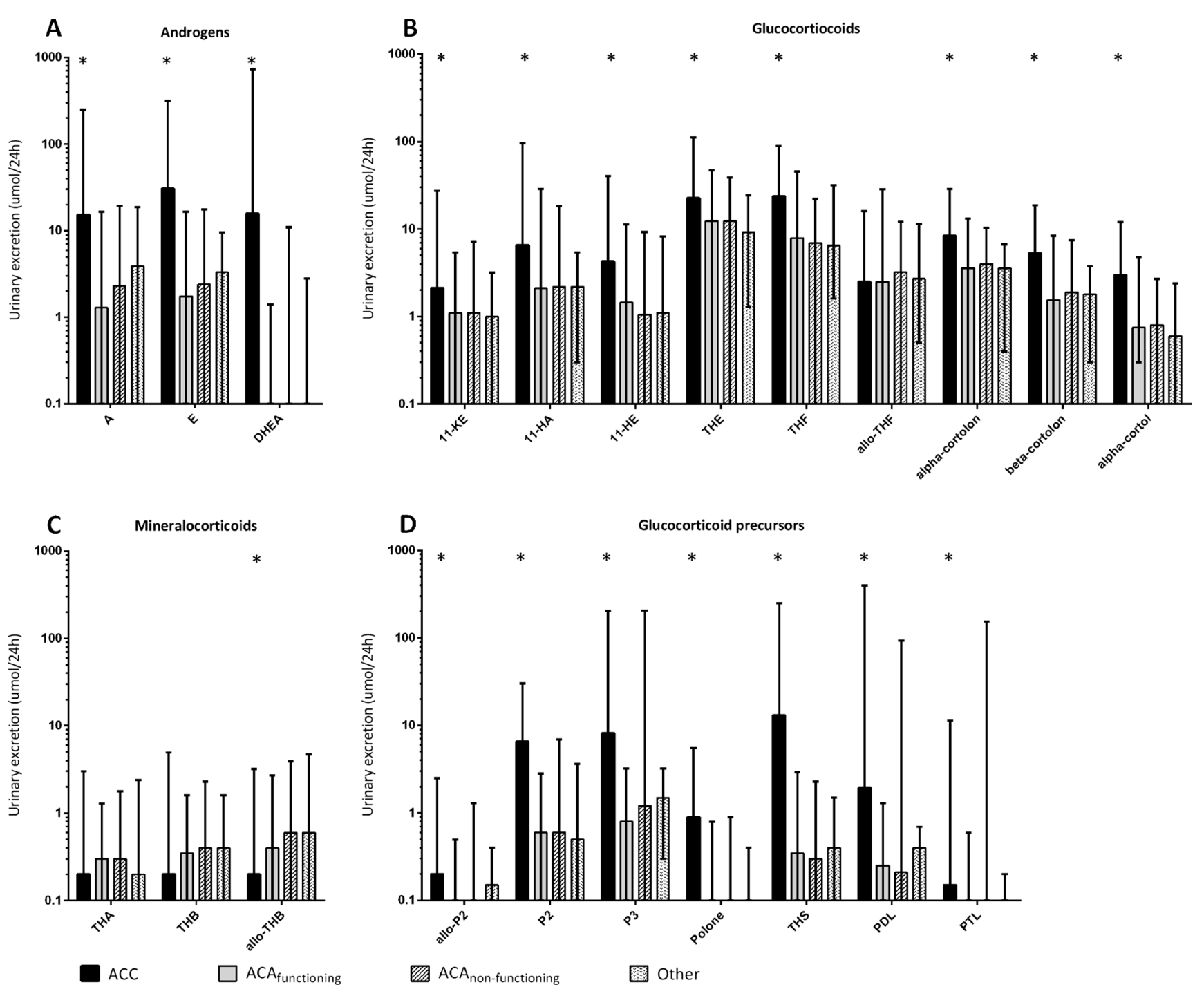

Fig. 1 a-d. Median urinary excretion of 22 metabolites in patients with ACC, functioning adenoma, non-functioning adenoma, or other adrenal tumors organized per steroid class. $A$ androsterone, $E$ etiocholanolone, DHEA dehydroepiandrosterone, 11-KE 11-keto-etiocholanolone, 11-HA 11-hydroxy-androsterone, 11-HE 11-hydroxy-eticholanolone, THE tetrahydrocortisone, THF tetrahydrocortisol, allo-THF allo-

ROC-analysis demonstrated that 15 steroid metabolites had a sensitivity $>90 \%$ for detecting ACC, of which 7 had a sensitivity of $100 \%$ (i.e., tetrahydro-11-deoxycortisol (THS), pregnanediol (P2), pregnanetriol (P3), etiocholanolone (E), androsterone, tetrahydrocortisol, and tetrahydrocortisone; Table 2). The ROC curve for THS was found to have the largest AUC (1.0), with a sensitivity of $100 \%$ and a specificity of $99 \%$ at a cut-off value of $2.35 \mu \mathrm{mol} / 24 \mathrm{~h}$ (Fig. 2). This cut-off value significantly exceeded each of the age and gender-specific upper reference limits. Median THS excretion in patients with ACC, ACA, or those belonging to the mixed group was $13.10 \mu \mathrm{mol} / 24 \mathrm{~h}$ (interquartile range $6.20-35.90 \mu \mathrm{mol} / 24 \mathrm{~h}$ ), $0.30 \mu \mathrm{mol} / 24 \mathrm{~h}$ (IQR $0.20-0.65 \mu \mathrm{mol} / 24 \mathrm{~h}$ ), and $0.40 \mu \mathrm{mol} / 24 \mathrm{~h}$ (IQR 0.20
Glucocorticoid precursors

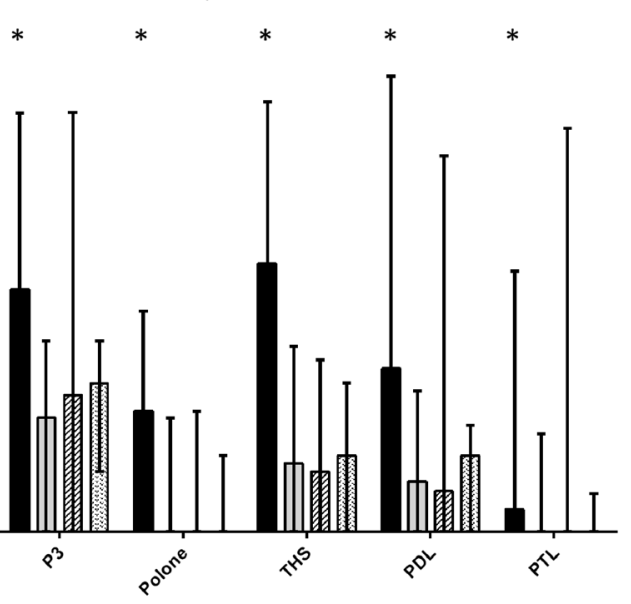

Other

tetrahydrocortisol, THA tetrahydro-11-dehydrocorticosterone, THB tetrahydrocorticosterone, allo- $T H B$ allo-tetrahydrocorticosterone, allo$P 2$ allo-pregnanediol, $P 2$ pregnanediol, P3 pregnanetriol, Polone epipregnanolone, THS tetrahydro-11-deoxycortisol, $P D L$ pregnanediolone, PTL pregnanetriolone. Whiskers indicate range, * indicates significant difference between ACC and other groups

$0.63 \mu \mathrm{mol} / 24 \mathrm{~h}$ ), respectively. Excluding patients in whom the adrenal tumor had a CT attenuation value $<10 \mathrm{HU}(n=37)$ did not affect the diagnostic performance of THS excretion (AUC 1.0). Figure 3 displays the relationship between cut-off values, reference intervals, and median excretion of four steroid metabolites showing the highest sensitivity and specificity (THS, P2, P3, E).

Median THS excretion in patients with ACC and ENSAT stages II, III, or IV was $8.70 \mu \mathrm{mol} / 24 \mathrm{~h}$ (range 2.40 $45.20 \mu \mathrm{mol} / 24 \mathrm{~h}$ ), $10.00 \mu \mathrm{mol} / 24 \mathrm{~h}$ (range 3.30 $39.20 \mu \mathrm{mol} / 24 \mathrm{~h}$ ), and $30.40 \mu \mathrm{mol} / 24 \mathrm{~h}$ (range 6.20 $250.00 \mu \mathrm{mol} / 24 \mathrm{~h})$, respectively $(P=0.025)$. Histopathological description of diameter and weight of the ACC was available for 23 and 13 patients, respectively. We found a 
Table 2 Receiver operating characteristics for individual steroid metabolites with sensitivity for detecting ACC $>90 \%$

\begin{tabular}{lllll}
\hline Metabolite & AUC & Cut-off value $(\mu \mathrm{mol} / 24 \mathrm{~h})$ & Sensitivity $(\%)$ & Specificity (\%) \\
\hline THS & 1.000 & 2.35 & 100 & 99 \\
P2 & 0.975 & 0.66 & 100 & 60 \\
P3 & 0.960 & 1.45 & 100 & 61 \\
E & 0.960 & 2.47 & 100 & 53 \\
A & 0.839 & 0.35 & 100 & 14 \\
THF & 0.806 & 2.10 & 100 & 5 \\
THE & 0.700 & 3.20 & 100 & 4 \\
PDL & 0.884 & 0.15 & 96 & 26 \\
$11-$ KE & 0.733 & 0.49 & 96 & 18 \\
$\beta$-cortolone & 0.793 & 0.45 & 96 & 7 \\
$\alpha$-cortolone & 0.760 & 0.75 & 96 & 4 \\
$\alpha$-cortol & 0.789 & 0.15 & 96 & 2 \\
11-HA & 0.699 & 0.15 & 96 & 25 \\
11-HE & 0.761 & 0.49 & 93 & 83 \\
Polone & 0.922 & 0.15 & 91 & 4 \\
\hline
\end{tabular}

$A U C$ area under curve, $T H S$ tetrahydro-11-deoxycortisol, $P 2$ pregnanediol, $P 3$ pregnanetriol, $E$ etiocholanolone, $A$ androsterone, THF tetrahydrocortisol, THE tetrahydrocortisone, $P D L$ pregnanediolon, 11-KE 11-keto-etiocholanolone, 11-HA 11-hydroxy-androsterone, 11-HE 11-hydroxy-eticholanolone, Polone epi-pregnanolone

significant correlation between THS excretion and ACC di- between THS excretion and ACC weight $(r=0.553$, ameter $(r=0.477, P=0.021)$ and a near-significant correlation $\quad P=0.050)$.

Fig. 2 a-d. Receiver operating characteristic (ROC) curve for tetrahydro-11-deoxycortisol, pregnanediol, pregnanetriol, and etiocholanolone for the diagnosis of adrenocortical carcinoma
A Tetrahydro-11-deoxycortisol (THS)

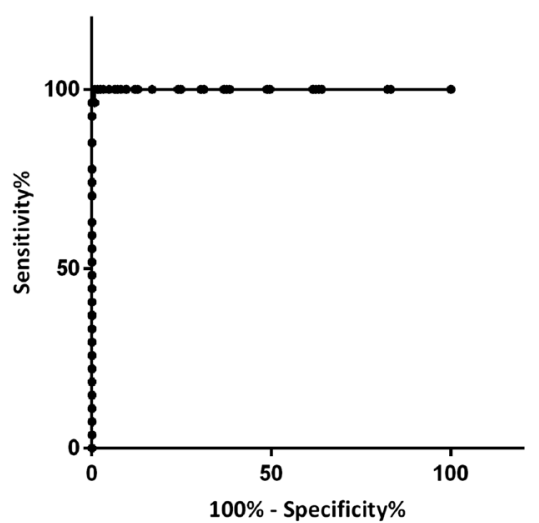

C

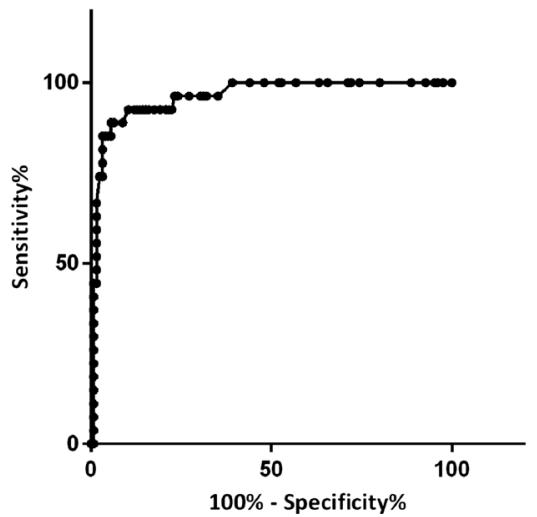

B Pregnanediol (P2)

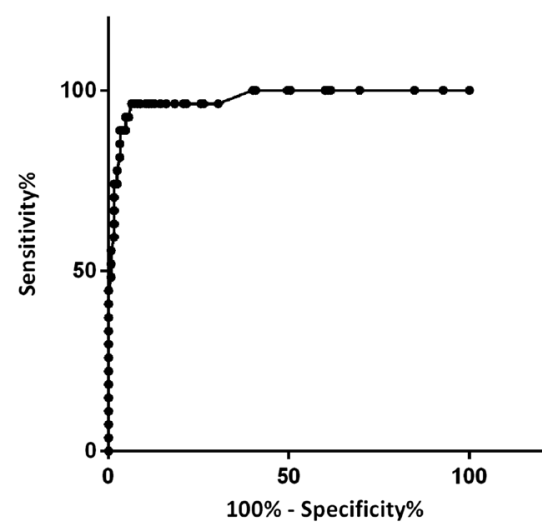

D

Etiocholanolone (E)

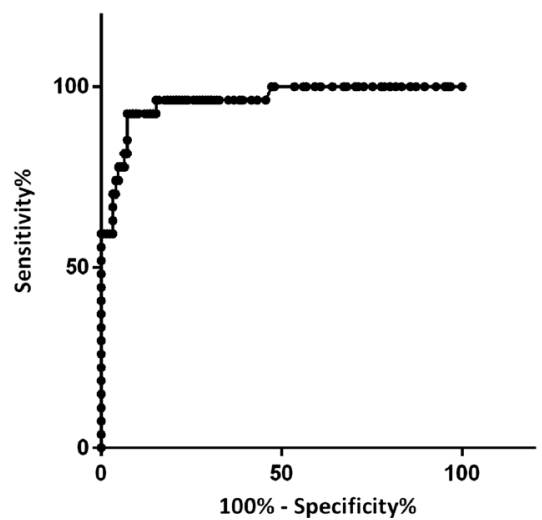



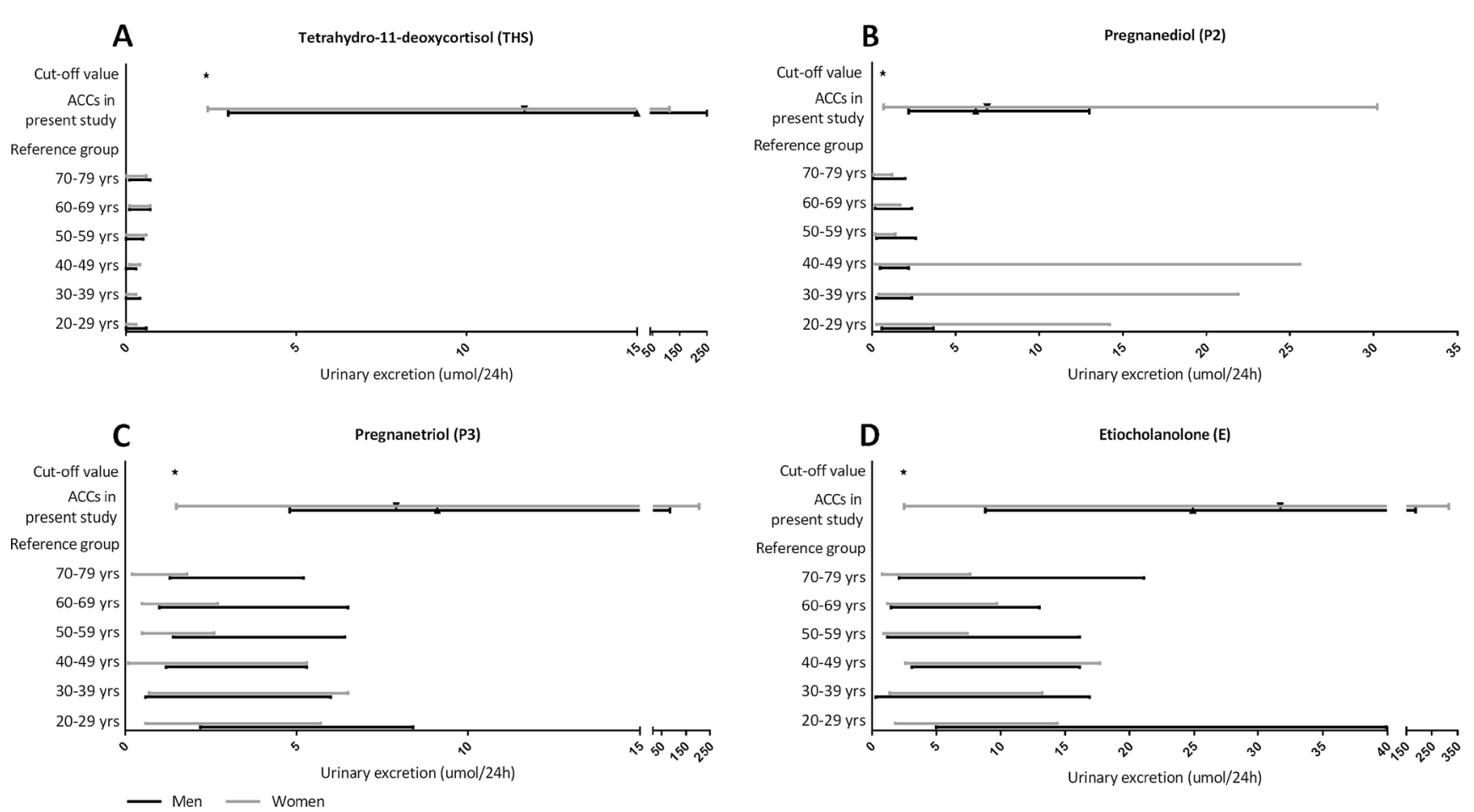

Fig. 3 a-d. Relationship between cut-off values, reference values, and measured urinary excretion of tetrahydro-11-deoxycortisol, pregnanediol, pregnanetriol, and etiocholanolone in 27 ACC patients

\section{Discussion}

In a relatively large cohort of patients with primary adrenal tumors, we found that urinary steroid profiling (USP) by gas chromatography/mass-spectrometry discriminates ACC from non-ACC with high diagnostic accuracy. In particular, we demonstrated that measurement of THS had the highest diagnostic test performance with a sensitivity and specificity of 100 and $99 \%$, respectively. In addition, THS excretion was significantly correlated with ACC tumor size and stage.

It has been demonstrated in several studies that USP may often reveal an increased excretion of steroid metabolites in patients with ACC, even in those without clinical signs of hormonal overproduction $[10,12,14,15,20]$. These observations suggest that USP might be a useful diagnostic tool in order to determine whether an adrenal tumor is either malignant or benign. Nearly all studies included a small number of patients with an adrenal tumor, limiting the external validity of these data. So far, only the study by Arlt et al. had a size comparable to the current series [13]. These investigators established a specificity and sensitivity of both $88 \%$ for the nine most differentiating steroid metabolites after conducting a more complex analysis, i.e., generalized matrix learning vector quantization. In addition, they also identified THS as the most discriminative steroid in differentiating benign from malignant adrenal tumors. There are some differences between the present study and the one by Arlt et al. which might explain why we established a higher diagnostic performance for USP. In all our subjects, USP was performed before removal of the primary ACC. In contrast, $22 \%$ of patients with ACC in the study by Arlt et al. were examined after removal of the primary tumor because of the presence of metastases. In view of the here described correlation between tumor size and THS excretion, it seems likely that the difference in diagnostic performance of USP can be partially explained by variation in tumor burden between the two populations at study. Presumably, a gradual increase in urinary THS occurs during development of metastatic disease. During follow-up after primary resection, THS levels below this cut-off value may not exclude the presence of residual or recurrent disease.

The etiology of THS overproduction in ACC remains speculative. Under physiological conditions, ACTH stimulates the conversion of free cholesterol to pregnenolone in mitochondria. Further steroid hormone biosynthesis takes place on the endoplasmic reticulum, except for the final steps in glucocorticoid and mineralocorticoid synthesis [21]. These reactions, catalyzed by CYP11B1 (11-deoxycortisol $\rightarrow$ cortisol) and CYP11B2 (11-deoxycorticosterone $\rightarrow$ aldosterone), take place on the inner mitochondrial membrane (IMM) and are stimulated by ACTH [22]. The abundant presence of THS, a metabolite of 11-deoxycortisol, suggests a relative deficiency of otherwise normally functioning CYP11B1 and/or dysfunction of the enzyme itself $[13,23]$. Possible explanations for a relative deficiency include increased production of steroid precursors upstream due to malignant proliferation or impaired access of substrate to the IMM. Dysfunction of CYP11B1 
may be caused by mutational changes inherent to ACC or diminished ACTH secretion due to negative feedback by increased levels of steroid precursors.

The results of our study suggest that USP could be a valuable diagnostic tool in analyzing an adrenal incidentaloma. Current diagnostic algorithms mainly depend on radiological characteristics for differentiation between benign and malignant adrenal tumors [1, 4-7]. CT scanning, however, has several disadvantages such as exposure to ionizing radiation, adverse effects of radiocontrast (nephropathy, allergic reactions), and costs [8]. Thus, USP might offer a patient friendly, entirely safe, and less expensive alternative diagnostic test for the evaluation of an adrenal incidentaloma. Further validation of this test is warranted and is the main objective of a recently started multicenter prospective study in the Netherlands (NCT02324647).

Like previous studies on this subject, the value of our study is limited by its retrospective design. In addition, selection bias could have influenced the results since it cannot be guaranteed that all patients with an adrenal tumor were evaluated with USP. Moreover, not all diagnoses were confirmed by histopathological examination. This is, however, in agreement with the clinical practice to exclude the diagnosis of ACC in case symptoms or signs suggestive for adrenal malignancy have not occurred during long-term follow-up of the patient.

In conclusion, USP might be a useful diagnostic tool for discriminating between benign and malignant adrenocortical tumors. In particular, increased urinary excretion of THS was associated with an almost perfect diagnostic power. Prospective studies are required to establish the true diagnostic value of USP in patients with an adrenal incidentaloma.

Conflict of Interest The authors declare that there is no conflict of interest that could be perceived as prejudicing the impartiality of the research reported.

Funding This research did not receive any grant from any funding agency in the public, commercial, or not-for-profit sector.

Open Access This article is distributed under the terms of the Creative Commons Attribution 4.0 International License (http:// creativecommons.org/licenses/by/4.0/), which permits unrestricted use, distribution, and reproduction in any medium, provided you give appropriate credit to the original author(s) and the source, provide a link to the Creative Commons license, and indicate if changes were made.

\section{References}

1. Young WF Jr (2007) Clinical practice. The incidentally discovered adrenal mass. N Engl J Med 356(1533-4406):601-610

2. Bovio S, Cataldi A, Reimondo G, Sperone P, Novello S, Berruti A, Borasio P, Fava C, Dogliotti L, Scagliotti GV, Angeli A, Terzolo M (2006) Prevalence of adrenal incidentaloma in a contemporary computerized tomography series. J Endocrinol Invest 29(03914097; 4):298-302

3. Kievit J, Haak HR (2000) Diagnosis and treatment of adrenal incidentaloma. A cost-effectiveness analysis. Endocrinol Metab Clin North Am 29(1):69-90, viii-ix

4. Grumbach MM, Biller BM, Braunstein GD, Campbell KK, Carney JA, Godley PA, Harris EL, Lee JK, Oertel YC, Posner MC, Schlechte JA, Wieand HS (2003) Management of the clinically inapparent adrenal mass ("incidentaloma"). Ann Intern Med 138(1539-3704; 5):424-429

5. Terzolo M, Stigliano A, Chiodini I, Loli P, Furlani L, Arnaldi G, Reimondo G, Pia A, Toscano V, Zini M, Borretta G, Papini E, Garofalo P, Allolio B, Dupas B, Mantero F, Tabarin A, Italian Association of Clinical Endocrinologists (2011) AME position statement on adrenal incidentaloma. Eur J Endocrinol 164(6): 851-870

6. Mansmann G, Lau J, Balk E, Rothberg M, Miyachi Y, Bornstein SR (2004) The clinically inapparent adrenal mass: update in diagnosis and management. Endocr Rev 25(2):309-340

7. Nieman LK (2010) Approach to the patient with an adrenal incidentaloma. J Clin Endocrinol Metab 95(9):4106-4113

8. Cawood TJ, Hunt PJ, O'Shea D, Cole D, Soule S (2009) Recommended evaluation of adrenal incidentalomas is costly, has high false-positive rates and confers a risk of fatal cancer that is similar to the risk of the adrenal lesion becoming malignant; time for a rethink? Eur J Endocrinol 161(4):513-527

9. Khorram-Manesh A, Ahlman H, Jansson S, Wangberg B, Nilsson O, Jakobsson CE, Eliasson B, Lindstedt S, Tisell LE (1998) Adrenocortical carcinoma: surgery and mitotane for treatment and steroid profiles for follow-up. World J Surg 22(0364-2313; 6):605611

10. Gröndal S, Eriksson B, Hagenas L, Werner S, Curstedt T (1990) Steroid profile in urine: a useful tool in the diagnosis and follow up of adrenocortical carcinoma. Acta Endocrinol (Copenh) 122(5): 656-663

11. Kouyama R, Hiraishi K, Sugiyama T, Izumiyama H, Yoshimoto T, Akashi T, Kihara K, Homma K, Shibata H, Hirata Y (2011) Clinicopathological features, biochemical and molecular markers in 5 patients with adrenocortical carcinoma. Endocr J 58(7):527534

12. Minowada S, Kinoshita K, Hara M, Isurugi K, Uchikawa T, Niijima $\mathrm{T}$ (1985) Measurement of urinary steroid profile in patients with adrenal tumor as a screening method for carcinoma. Endocrinol Jpn 32(1):29-37

13. Arlt W, Biehl M, Taylor AE, Hahner S, Libe R, Hughes BA, Schneider P, Smith DJ, Stiekema H, Krone N, Porfiri E, Opocher G, Bertherat J, Mantero F, Allolio B, Terzolo M, Nightingale P, Shackleton CH, Bertagna X, Fassnacht M, Stewart PM (2011) Urine steroid metabolomics as a biomarker tool for detecting malignancy in adrenal tumors. J Clin Endocrinol Metab 96(12):37753784

14. Tiu SC, Chan AO, Taylor NF, Lee CY, Loung PY, Choi CH, Shek CC (2009) Use of urinary steroid profiling for diagnosing and monitoring adrenocortical tumours. Hong Kong Med J 15(6):463-470

15. Kotlowska A, Sworczak K, Stepnowski P (2011) Urine metabolomics analysis for adrenal incidentaloma activity detection and biomarker discovery. J Chromatogr B Analyt Technol Biomed Life Sci 879(5-6):359-363

16. Fassnacht $\mathrm{M}$, Johanssen S, Quinkler M, Bucsky P, Willenberg HS, Beuschlein F, Terzolo M, Mueller HH, Hahner S, Allolio B, German Adrenocortical Carcinoma Registry Group, European Network for the Study of Adrenal Tumors (2009) Limited prognostic value of the 2004 international union against cancer staging classification 
for adrenocortical carcinoma: proposal for a revised TNM classification. Cancer 115(2):243-250

17. Weiss LM, Medeiros LJ, Vickery AL Jr (1989) Pathologic features of prognostic significance in adrenocortical carcinoma. Am J Surg Pathol 13(0147-5185; 3):202-206

18. Wolthers BG, Kraan GP (1999) Clinical applications of gas chromatography and gas chromatography-mass spectrometry of steroids. J Chromatogr A 843(1-2):247-274

19. Stolk RP, Rosmalen JG, Postma DS, de Boer RA, Navis G, Slaets JP, Ormel J, Wolffenbuttel BH (2008) Universal risk factors for multifactorial diseases: LifeLines: a three-generation populationbased study. Eur J Epidemiol 23(1):67-74

20. Lipsett MB, Hertz R, Ross GT (1963) Clinical and pathophysiologic aspects of adrenocortical carcinoma. Am J Med 35(0002-9343):374-383
21. Hanukoglu I (1992) Steroidogenic enzymes: structure, function, and role in regulation of steroid hormone biosynthesis. J Steroid Biochem Mol Biol 43(8):779-804

22. Miller WL, Auchus RJ (2011) The molecular biology, biochemistry, and physiology of human steroidogenesis and its disorders. Endocr Rev 32(1):81-151

23. Sasano H, Suzuki T, Nagura H, Nishikawa T (1993) Steroidogenesis in human adrenocortical carcinoma: biochemical activities, immunohistochemistry, and in situ hybridization of steroidogenic enzymes and histopathologic study in nine cases. Hum Pathol 24(0046-8177; 4):397404 